\title{
Hospital with Medicare Approved Swing Bed
}

National Cancer Institute

\section{Source}

National Cancer Institute. Hospital with Medicare Approved Swing Bed. NCI Thesaurus.

Code C99960.

A medical center with a swing type of hospital bed that will be paid for my Medicare. (ACC) 